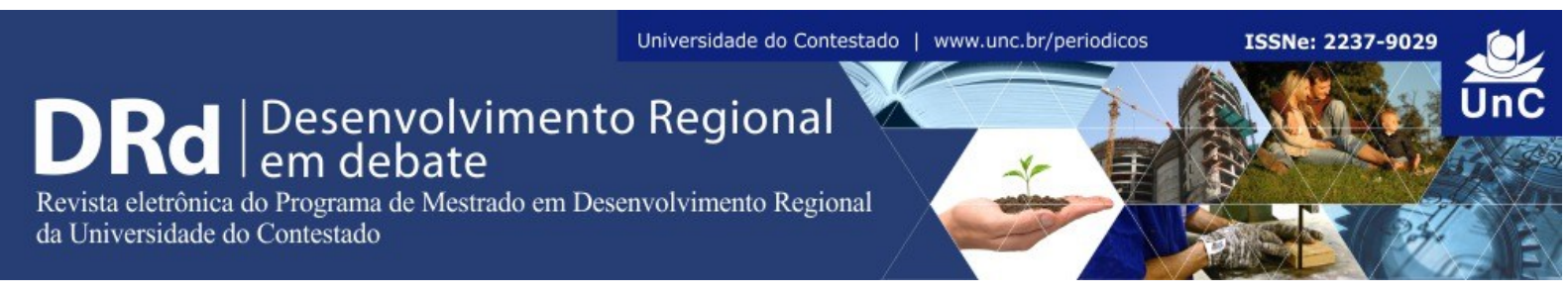

\title{
MELHORIA DA PRODUÇÃO ANIMAL EM ÁREAS DE CAÍVA E SUA CONTRIBUIÇÃO PARA A VIABILIZAÇÃO DE CORREDORES ECOLÓGICOS
}

\author{
Ana Lúcia Hanisch ${ }^{1}$ \\ Maria Izabel Radomski ${ }^{2}$ \\ Luis Cláudio Bona ${ }^{3}$ \\ Anésio da Cunha Marques ${ }^{4}$
}

\begin{abstract}
RESUMO
Ao longo da última década, entidades de pesquisa vêm desenvolvendo tecnologias que promovam o aumento da produção animal nos sistemas silvipastoris tradicionais característicos do Planalto Norte Catarinense, localmente denominados de caívas. As caívas são áreas de remanescentes de Floresta Ombrófila Mista (FOM) com tamanhos variados, historicamente manejados para extração de erva-mate e manutenção de rebanhos animais. Desempenham importante papel na preservação dessa formação florestal, bem como na conectividade de áreas florestais. Dessa forma, as caívas apresentam potencial para atender às premissas do Programa de Corredores Ecológicos em SC, cujo objetivo é contribuir na conservação da biodiversidade, restaurando a conectividade da paisagem por meio do desenvolvimento de práticas de baixo impacto nestas áreas. No entanto, ainda há poucas tecnologias viáveis para uso econômico em remanescentes de FOM. A existência das caívas como sistemas tradicionais de uso das florestas precisa ser melhor compreendida e valorizada, bem como necessita que sejam geradas tecnologias adaptadas a esse sistema. O manejo tradicional das caívas tem sido constantemente ameaçado, em função da baixa geração de renda. A melhoria das caívas para produção animal tem se caracterizado como uma alternativa promissora, embora a legislação apresente restrições ao uso de animais em remanescentes florestais. Por outro lado, há de se considerar que as caívas só existem em função de seu histórico de uso múltiplo, associando produção de erva-mate, pinhão, frutas nativas e a criação animal. Este trabalho busca contextualizar os principais avanços tecnológicos gerados para manejo animal nas caívas e como sua adoção pode contribuir para a sustentabilidade das mesmas, bem como para o sucesso na implantação de Corredores Ecológicos.
\end{abstract}

Palavras-chave: Conservação Ambiental. Erva-mate. Floresta Ombrófila Mista. Pastagem. Sistema Silvipastoril.

\footnotetext{
${ }^{1}$ Engenheira Agrônoma, pesquisadora da Epagri/Estação Experimental de Canoinhas (SC), doutoranda do Programa de Pós Graduação em Produção Vegetal da Universidade Federal do Paraná. Santa Catarina. Brasil. E-mail: analucia@epagri.sc.gov.br.

${ }^{2}$ Graduação e doutorado em Agronomia, Pesquisadora Embrapa Florestas. E-mail: maria.radomski@embrapa.br ${ }^{3}$ Engenheiro Agrônomo, Especialista em Agroecologia. Santa Catarina. Brasil. E-mail: lcbona@gmail.com

${ }^{4}$ Engenheiro Agrônomo, doutor em Desenvolvimento e Meio Ambiente na UFPR, com atuação no ICMBIO, Floresta Nacional de Três Barras (Santa Catarina-Brasil). Santa Catarina. Brasil. E-mail: anesio.marques@gmail.com
}

DRd - Desenvolvimento Regional em debate (ISSNe 2237-9029)

v. 6, n. 2, ed. esp., p. 170-188, jul. 2016. 


\title{
ABSTRACT \\ IMPROVEMENT OF ANIMAL PRODUCTION IN CAÍVA AREAS FOR CONTRIBUTE TO DEPLOYMENT OF ECOLOGICAL CORRIDORS
}

Over the past decade, research institutions have developed technologies that promote the increase of animal production in traditional silvopastoral systems characteristic of the North Plateau of Santa Catarina, locally called caívas. The caívas are areas of forest remnants with varying sizes, historically managed to extract yerba mate and keeping livestock. They show the presence of species of Araucaria Forest and thus play an important role in the preservation of this biome, as well as the connectivity of forest areas. Thus, caívas have the potential to meet the assumptions of the Ecological Corridors Program in SC, which aims to contribute to the conservation of biodiversity, restoring the landscape connectivity through the development of low impact practices in these areas. However, there are still few viable technologies for economic use in remaining FOM. The existence of caívas as traditional systems of forest use needs to be better understood and valued and technologies adapted to this system. Maintaining caívas the traditional model has been constantly threatened, due to low income generation. Improving caívas to animal production has been characterized as a promising alternative, although legislation has restrictions on the use of animals in forest remnants. On the other hand, it should also consider that caívas exist only because of its historical multiple use, like yerba, pine nut and native fruits production and animal husbandry. This paper seeks to contextualize the main technological advances generated for animal management in caívas and how its adoption can contribute to the sustainability of these as well as for the successful implementation of Ecological Corridors.

Keywords: Environmental Conservation. Yerba Mate. Araucaria Forest. Pasture. Silvopastoral Systems

\section{INTRODUÇÃO}

\begin{abstract}
Ao rodar pelas estradas no Planalto Norte de Santa Catarina os viajantes se deparam com uma paisagem composta por um mosaico formado por remanescentes de floresta de araucárias entremeados por lavouras anuais e cultivos florestais. Em vários trechos da estrada é possível visualizar o gado bovino pastando à sombra desses remanescentes florestais. A formação dessa paisagem se deve em grande medida à permanência de um sistema produtivo tradicional dessa região conhecido como caívas ou invernadas (BONA; HANISCH; MARQUES, 2011, p. 6).
\end{abstract}

A descrição acima representa bem a beleza das paisagens naturais do Planalto Norte Catarinense. Para muitos viajantes é quase incompreensível a presença de áreas de remanescentes florestais em solos agricultáveis. No entanto, para os agricultores da região, as caívas são mais que áreas de cultivo. São história, seguro e tradição.

As caívas são as áreas onde ocorre a produção de erva-mate (Ilex paraguaiensis) associada à presença de pastagens naturalizadas utilizadas para manutenção de rebanhos animais (HANISCH et al., 2010). São ecossistemas associados da Floresta Ombrófila Mista (FOM), que foram mantidos nas propriedades rurais como áreas de múltiplo uso, sendo utilizados para extração de erva-mate para comercialização, de lenha, madeira, medicamentos e frutas nativas para consumo familiar e de pastejo para manutenção dos rebanhos bovinos

DRd - Desenvolvimento Regional em debate (ISSNe 2237-9029) 
(BONA; HANISCH; MARQUES, 2011; MELLO; PERONI, 2015). As caívas estão incorporadas à cultura local há décadas, e estima-se sua presença em aproximadamente $30 \%$ dos estabelecimentos rurais da região, com uma área entre 100.000 e 130.000 hectares (IBGE, $2006)^{5}$.

Além da importância socioeconômica, as caívas possuem elevada importância ambiental, considerando-se a intensa degradação florestal ocorrida na região nos últimos 50 anos. Se não fosse por seu propósito econômico por meio do extrativismo e pastejo, grande parte das atuais áreas de caíva não existiria. Ou seja, se por um lado a pressão animal é considerada o principal problema da degradação dos ervais em meio às florestas, a produção animal é considerada um dos principais usos dessas paisagens (MARQUES, 2014).

\section{A CONTRIBUIÇÃo dAS CAÍVAS PARA OS CORREDORES ECOLÓGICOS}

As características naturais e o manejo histórico das caívas conferem-lhes uma contribuição natural para a viabilização do processo de formação de corredores ecológicos, uma vez que desempenham essa função naturalmente, por serem fragmentos de FOM. Com frequência os fragmentos de caíva são próximos ou conectados uns aos outros. Dessa forma, as caívas são um agroecossistema ideal para promoção de práticas sustentáveis, de baixo impacto e com geração de renda, que podem atender às premissas da proposta de Corredores Ecológicos.

De acordo com o Ministério do Meio Ambiente (2007) o Projeto Corredores Ecológicos, faz parte do Programa Piloto para a Proteção das Florestas Tropicais do Brasil e objetiva contribuir para a conservação efetiva da biodiversidade por intermédio de uma abordagem inovadora que propõe a criação de corredores de floresta tropical em dois dos mais importantes biomas brasileiros: a Floresta Amazônica e a Mata Atlântica.

Os corredores foram concebidos como forma de conectar áreas protegidas, mantendo ou restaurando a conectividade da paisagem e facilitando o fluxo genético entre populações por meio de alternativas para o desenvolvimento de práticas de pouco impacto nas áreas de interstícios (BRASIL. MINISTÉRIO DO MEIO AMBIENTE, 2015).

Em Santa Catarina, desde 2010, por meio de decretos, o Governo do Estado está implementando dois Corredores Ecológicos nas Bacias Hidrográficas dos rios Chapecó e Timbó, sendo que neste são abrangidos municípios do Planalto Norte Catarinense (Figura 1). A área dos dois corredores, que soma mais de 10 mil km² em 34 municípios, corresponde a $10,7 \%$ da área do território catarinense.

\footnotetext{
${ }^{5}$ Para o cálculo estimado de caívas no Planalto Norte foi utilizado a somatória de pastagens naturais $+50 \%$ dos sistemas agroflorestais $+20 \%$ do item matas e florestas (fora RL e APP).
} 
Figura 1 - Mapa da área dos dois Corredores Ecológicos no Estado de Santa Catarina, Brasil

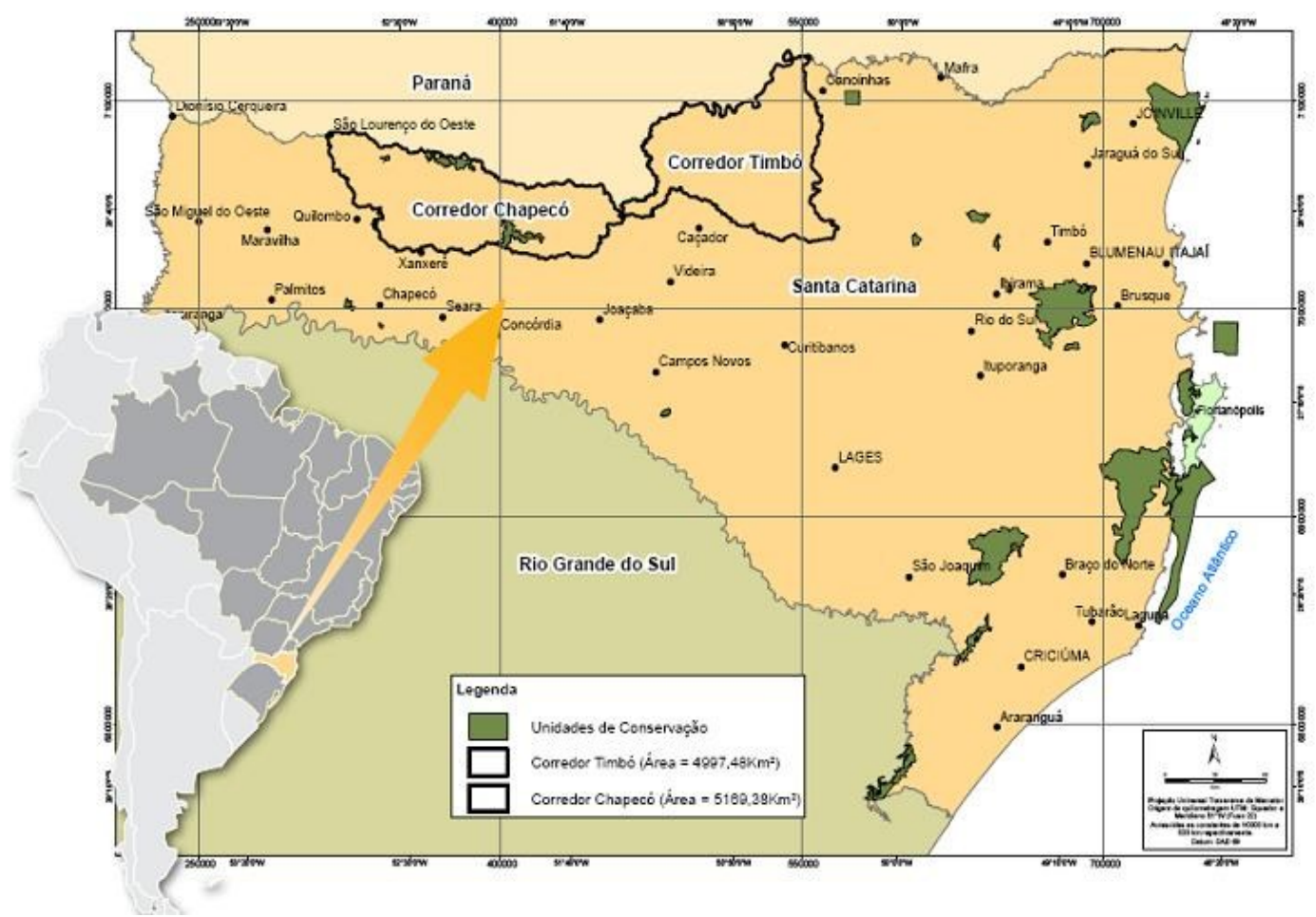

Fonte: Fatma (2016)

De acordo com a Fundação do Meio Ambiente de Santa Catarina (FATMA), o Corredor Ecológico é uma área com remanescentes de vegetação nativa, cujo objetivo é unir a conservação da natureza ao desenvolvimento local e regional, integrando o desenvolvimento econômico à conservação da biodiversidade, sendo voluntária a participação dos produtores rurais. Para atender a esse objetivo são necessárias tecnologias que se adequem ao processo de uso e manejo de áreas de remanescentes florestais, ou seja, que gerem renda com baixo impacto ambiental. No entanto, há pouquíssimas alternativas econômicas para remanescentes de FOM além da extração da erva-mate.

\section{O MANEJO TRADICIONAL DAS CAÍVAS}

Apesar da importância socioambiental das caívas, a baixa viabilidade econômica é uma realidade que pressiona os proprietários para substituição dessas áreas por reflorestamentos de pinus e eucalipto ou até mesmo, abertura da área para cultivos anuais, ameaçando sua existência na região. De forma geral, a baixa rentabilidade das caívas está associada ao preço historicamente flutuante da erva-mate, à degradação dos ervais e, em especial à baixa produtividade animal.

O manejo tradicional das pastagens nas áreas de caíva é o de pastejo contínuo, com os animais, predominantemente bovinos, criados soltos na área. Esse manejo conduz a uma pressão de pastejo excessiva nas caívas, especialmente em determinadas épocas do ano. Em propriedades menores é comum os animais ficarem na caíva apenas na época de cultivo de verão, em função das pequenas áreas de lavoura. Uma variante é o manejo em que os animais 
recebem alimentação no cocho ou permanecem em áreas de pastagens cultivadas por algumas horas por dia e passam o resto do tempo nas caívas

Além do excesso de pastejo, que contribuiu para a compactação do solo, outra característica do manejo tradicional é a ausência da reposição de nutrientes no solo, ou seja, raramente ocorrem adubações nas áreas de caíva, apesar do uso contínuo por décadas. Essas características do manejo, associadas às características naturais dos solos da região, de elevada acidez e baixa saturação de bases, conduz à baixa produtividade dessas áreas.

Neste cenário, as pastagens adaptadas a esse ambiente caracterizam-se por espécies resistentes à baixa fertilidade do solo, com moderada tolerância ao sombreamento e ao pisoteio. Como consequência deste conjunto de fatores, a produção de pasto nessas áreas é muito baixa - cessando, inclusive, nos meses de outono-inverno - o que acarreta em baixa produtividade animal, seja de carne ou leite, tornando esse sistema produtivo pouco interessante sob a ótica econômica atual (HANISCH; BONA; MARQUES, 2009). Além, é claro, de que em determinadas situações ocorre a supressão da regeneração florestal através do pastejo de mudas de espécies florestais nativas, em função da baixa ou nula oferta de pasto em determinadas épocas do ano.

Apesar dessas características, as caívas seguem seu curso como áreas de conservação de remanescentes de FOM, sendo este manejo paradoxalmente, um dos principais contribuintes para a conservação dessas áreas (MARQUES, 2014). Isso ocorre porque o manejo tradicional, passado de pai para filho ao longo de décadas, busca acima de tudo, conservar estas áreas para a atividade ervateira. Dessa forma, o manejo tradicional contribui com a conservação da FOM através de práticas geradas por meio do conhecimento empírico como: 1) a retirada dos animais das caívas quando esta começa a apresentar sintomas de degradação; 2) o controle da carga animal em determinadas épocas do ano a fim de permitir o crescimento da erva-mate; 3) o controle da vegetação excessiva via roçada a fim de evitar excesso de sombra e a morte das pastagens adaptadas a esse ambiente (MATOS, 2011; MARQUES, 2014).

\section{A CONSTRUÇÃO PARTICIPATIVA DE UM NOVO MODELO DE USO DAS CAÍVAS A PARTIR DO PROJETO DE VALIDAÇÃO DO USO DE PASTAGENS PERENES NO PLANALTO NORTE CATARINENSE}

Em 2004 a Epagri - Estação Experimental de Canoinhas (EECan) iniciou um projeto em parceria com o Ministério do Desenvolvimento Agrário para validação de tecnologias adaptadas à agricultura familiar. $\mathrm{O}$ objetivo do projeto era implantar 10 unidades de validação no território em propriedades familiares e com o apoio da pesquisa dar início ao trabalho de avaliação da adaptação de algumas espécies de pastagens perenes às condições edafoclimáticas da região.

Foram selecionadas, em parceria com a extensão rural da Epagri e com entidades parcerias como o Sindicato dos Trabalhadores da Agricultura Familiar e a Casa Familiar Rural de Major Vieira, dez famílias distribuídas nos municípios de Porto União, Irineópolis, Canoinhas, Três Barras, Major Vieira e Mafra (Figura 2). 
Figura 2 - Distribuição das dez unidades de validação de tecnologia para produção de leite a base de pastagens perenes no Planalto Norte Catarinense em propriedades familiares

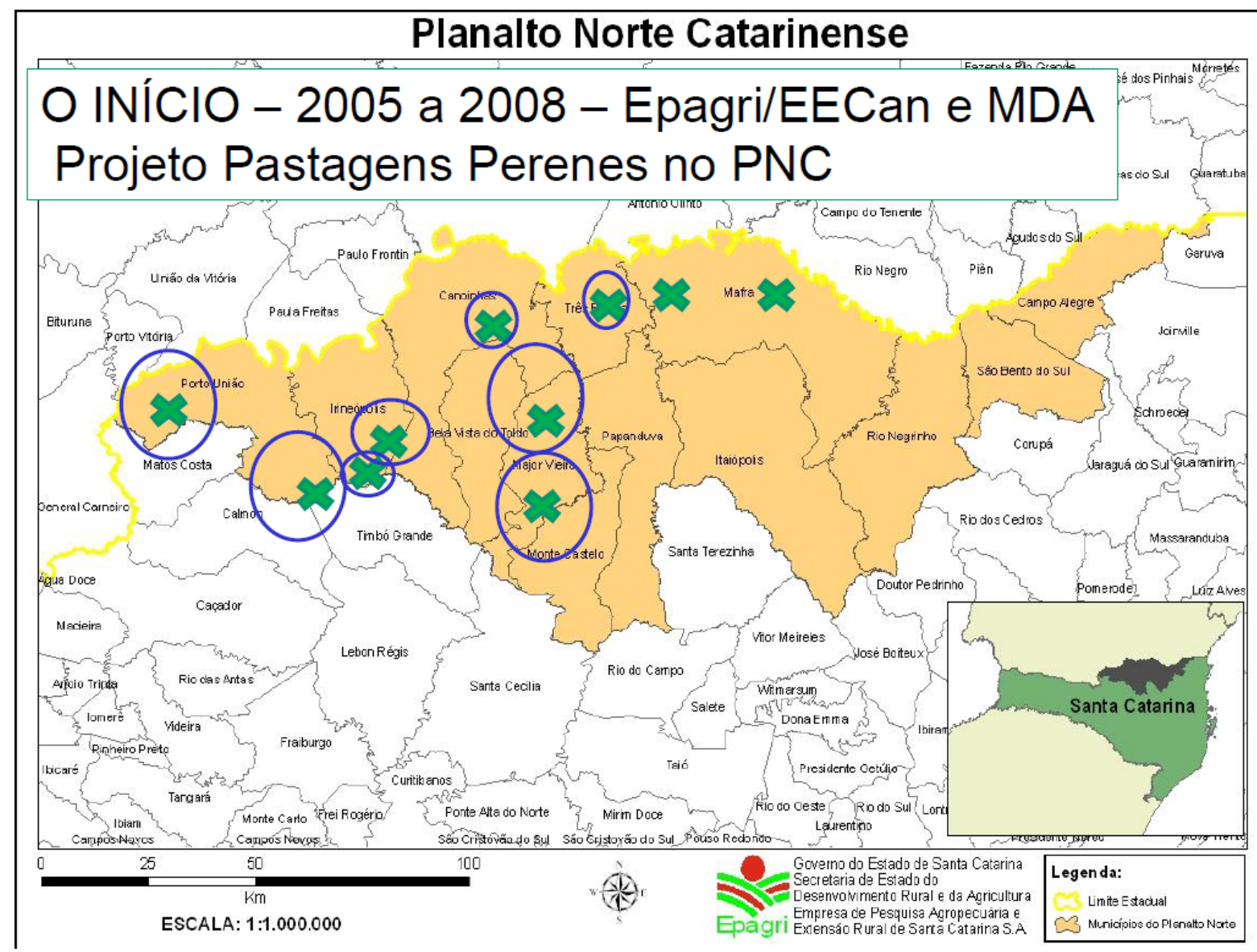

Fonte: Elaborado pelos autores a partir de informações da Epagri/Ciram (2006)

Em cada uma das propriedades foi implantado um hectare de pastagem perene, com diferentes espécies: Hemarthria altíssima cv. Flórida, capim-elefante cv. Pioneiro (Pennisetum purpureum) e missioneira-gigante (Axonopus catharinensis). Todo o processo de implantação, desenvolvimento das pastagens, piqueteamento, manejo do pastejo, entre outros, era realizado através do monitoramento de um Grupo Gestor, composto pelas dez famílias, os técnicos e pesquisadores envolvidos, lideranças e convidados. Para isso, ocorriam encontros periódicos a cada dois meses, cada vez em uma das unidades de validação tecnológica, onde eram realizadas as avaliações para cada situação específica. Na sequência eram debatidos os resultados e comparados com as demais propriedades ${ }^{6}$.

Além das reuniões periódicas do Grupo Gestor que foram fundamentais para o sucesso e disseminação da prática da produção de leite a base de pastagens perenes no Planalto Norte, cada propriedade ficava aberta à visitação de grupos de outros municípios, sendo que algumas das propriedades receberam centenas de visitantes durante o período do projeto.

No âmbito local, ocorriam ainda as reuniões de grupo de famílias, conduzidas pelos extensionistas do município onde se localizava a unidade de validação. Dessa forma, no ${ }^{6}$ Outras informações sobre o Projeto de Produção de Leite a Base de Pastagens Perenes no Planalto Norte (2005-
2008) ou sobre os resultados das avaliações podem ser obtidos em Hanisch e Meister (2009). 
entorno das unidades foram sendo desenvolvidos grupos organizados de produtores de leite que foram aprendendo a utilizar as pastagens perenes mais adaptadas a cada situação. Em função da dinâmica de cada extensionista, os grupos eram maiores ou menores e com diferentes intensidades de atuação (tamanho do círculo no entorno da unidade na Figura 2).

Com o resultado na produção das pastagens perenes, várias famílias que participavam das reuniões dos grupos locais ou mesmo do Grupo Gestor e que possuíam áreas de caívas começaram a demandar informações sobre a possibilidade de melhorar as pastagens naturalizadas, uma vez que a produção das pastagens introduzidas era incomparavelmente maior que a produção obtida tradicionalmente nas áreas de caíva.

Dessa forma, buscando atender a demanda de muitas famílias rurais proprietárias de caívas a EECan iniciou em 2006, um processo de pesquisa nestas áreas, com o objetivo de desenvolver tecnologias que visassem o aumento da produção de pasto e consequentemente da produção animal neste sistema. Por serem áreas de remanescentes florestais as pesquisas sempre visaram desenvolver tecnologias com baixo impacto ambiental, mas que pudessem promover melhoria considerável no sistema produtivo, o que igualmente, atende aos objetivos do Programa de Corredores Ecológicos.

O viés dessas pesquisas até hoje é aprimorar o sistema de uso e manejo sustentável desses remanescentes, o que significa administrar a floresta para obtenção de benefícios sociais, ambientais e econômicos, respeitando-se os mecanismos de sustentação do ecossistema objeto do manejo (ROSOT, 2007).

Tecnicamente, as caívas são sistemas silvipastoris naturais e como tal, com manejo adequado, podem aportar vários benefícios para a produção animal, como conforto térmico aos animais, melhoria da qualidade das pastagens e redução de danos provocados pelas geadas (RIBASKI et al., 2005).

Nas áreas de caíva, devido à presença de árvores e grande quantidade de raízes, todos os processos de melhoria da qualidade do solo e da pastagem devem ser realizados de forma criteriosa. A introdução de insumos deve evitar alterações de grande magnitude nas características químicas do solo, em curto prazo, uma vez que as espécies existentes neste sistema, em especial as espécies arbóreas, estão altamente adaptadas às estas condições e precisam ser mantidas neste ambiente. $\mathrm{O}$ uso de insumos agroecológicos como pós de rocha e estercos pode ser uma alternativa mais apropriada e de baixo impacto ambiental, devido à menor solubilidade destes produtos (FERREIRA et al., 2009).

As pesquisas em melhoria da produção animal em caívas vem sendo desenvolvidas em quatro fases: as duas primeiras fases ocorreram de 2007 a 2008 e de 2008 a 2009 e envolveram a Estação Experimental de Canoinhas, o Instituto Chico Mendes de Biodiversidade - Flona de Três Barras, a ONG AS-PTA, o Projeto Microbacias II e um Grupo Gestor das Caívas formado por seis famílias de agricultores familiares dos municípios de Canoinhas, Major Vieira, Três Barras e Bela Vista do Toldo nos quais foram desenvolvidas as pesquisas.

A terceira fase, de 2010 a 2012, buscou priorizar o desenvolvimento da melhoria da produção animal em áreas de caíva com predominância de erva-mate e priorizando-se o uso de insumos regionais como os resíduos da indústria de celulose. Foi desenvolvida pela Epagri/EECan com apoio da Fapesc. 
A quarta fase de pesquisa, teve início em 2011 e segue atualmente, com o desenvolvimento de um novo processo tecnológico. Conta com a parceria entre Epagri/EECan, Programa SC Rural, Embrapa Florestas, Flona Três Barras e Universidade Federal do Paraná.

Em função da heterogeneidade natural das caívas, seja no formato dos remanescentes florestais, ou seja, no manejo adotado, as pesquisas foram desenvolvidas por meio dos princípios da pesquisa participativa, com experimentos sendo implantados em diferentes caívas do Planalto Norte, em propriedades rurais que desenvolvem a atividade leiteira.

A pesquisa participativa é uma estratégia que tende a melhorar o planejamento, a condução, a avaliação, a interpretação dos resultados e a difusão do conhecimento gerado, sem prescindir de critérios adotados com rigor metodológico.

Este trabalho procura descrever resumidamente as principais pesquisas desenvolvidas em cada uma das fases, os principais avanços tecnológicos gerados para manejo animal nas caívas e como sua adoção pode contribuir para a sustentabilidade das mesmas, bem como para o sucesso na implantação de Corredores Ecológicos.

\section{MATERIAL E MÉTODOS}

\section{PRIMEIRA E SEGUNDA FASES DA PESQUISA (2007 a 2009)}

A primeira fase envolveu três propriedades rurais, sendo uma em Canoinhas e duas em Major Vieira onde teve início a construção da primeira proposta de melhoria das caívas: a de sobressemeadura de pastagem no inverno. Foram utilizadas técnicas consagradas em sistemas de produção animal a pasto, como piqueteamento, adubação em cobertura e sobressemeadura da pastagem com forrageiras anuais de inverno como azevém (Lolium multiflorum) e ervilhaca (Vicia sativa).

Foi implantado um experimento em blocos, com três repetições, cada uma formada por uma área de um hectare de caíva, onde foram avaliados diferentes tratamentos de adubação da pastagem: Tratamento (1), $2 \mathrm{t} / \mathrm{ha}^{7}$ de calcário dolomítico $+400 \mathrm{~kg} / \mathrm{ha}$ de fosfato natural de Gafsa +2 t/ha de cama de aviário; Tratamento (2), $800 \mathrm{~kg} / \mathrm{ha}$ de fosfato natural de Gafsa; Tratamento (3), 2 t/ha de pó de basalto; Tratamento (4), sem adubação (caíva tradicional). Todas as caívas experimentais foram piqueteadas e sobressemeadas no inverno e pastejadas por vacas leiteiras. Nestas áreas foram avaliadas a produção da pastagem e a caracterização do solo no início e no final do experimento ${ }^{8}$.

A segunda fase ocorreu quase que simultaneamente à primeira, em função de que, com o sucesso dos resultados observados no primeiro ano, novas famílias e entidades de pesquisa e extensão mostraram interesse em participar deste projeto.

\footnotetext{
${ }^{7} \mathrm{t} / \mathrm{ha}=$ toneladas por hectare

${ }^{8}$ Maiores informações sobre a metodologia utilizada podem ser acessadas em Hanisch, Bona e Marques (2009).
} 
Dessa forma, com a mesma metodologia de trabalho, foram inseridas mais duas áreas de caíva como unidades experimentais, uma no município de Bela Vista do Toldo e outra em Três Barras, totalizando cinco repetições. Com o aumento do número de envolvidos foi criado o Grupo Gestor de Caívas, formado pelas famílias, pesquisadores, extensionistas e convidados $^{9}$. Nesta fase da pesquisa, além da repetição do experimento com insumos agroecológicos para aprofundar as avalições na produção das pastagens e nas alterações no solo das caívas, foi também realizado um estudo inédito sobre a composição florística e a fitossociologia do estrato arbóreo das caívas (HANISCH et al., 2010).

Ao final da segunda fase da pesquisa, foi realizado um Diagnóstico Rápido Participativo com o Grupo Gestor, cujos resultados contribuíram para a continuação da pesquisa, em especial para o avanço da fase quatro.

\section{TERCEIRA FASE: A INTEGRAÇÃO COM A ERVA-MATE}

Embora a erva-mate estivesse presente nas cinco caívas pesquisadas nas fases anteriores, não era a espécie arbórea dominante em todas elas. Além disso, havia uma forte demanda dos agricultores (as) sobre o uso de insumos regionais da indústria de celulose que vinham sendo pesquisados pela EECan e apresentavam alta disponibilidade na região.

Buscando atender a essas duas demandas, foi desenvolvido por dois anos e com apoio da FAPESC, um experimento em caíva típica da região, com predominância de erva-mate no estrato arbóreo, localizada no município de Canoinhas.

O experimento foi realizado em delineamento em blocos casualizados, com três repetições, e oito tratamentos formados por diferentes combinações entre os insumos fosfato natural e cinza calcítica. Manteve-se a proposta de piqueteamento e sobressemeadura de inverno. Foram avaliadas a produção da pastagem ao longo do ano e as alterações nas características do solo, além de ter sido dado início à avaliação do sombreamento das áreas ${ }^{10}$.

\section{QUARTA FASE: A MISSIONEIRA-GIGANTE NO SISTEMA CAÍVA}

Após quase seis anos de pesquisas e com o registro do processo tecnológico de melhoria das áreas de caívas com sobressemeadura de inverno no banco de tecnologias da Epagri e divulgação do mesmo na região, houve necessidade de se pesquisar estratégias de melhoria para essas áreas durante o período de verão.

Após várias prospecções com forrageiras perenes de verão, os resultados foram bastante promissores para a espécie missioneira-gigante (Axonopus catharinensis cv. Catarina Gigante). A fim de aprofundar as análises foram implantados dois experimentos: 1) avaliação do potencial da missioneira-gigante em áreas de caíva, implantada após dessecação da pastagem naturalizada e manejada em diferentes alturas e níveis de sombra. Este experimento ocorreu em uma caíva do município de Porto União, com apoio do Programa SC Rural.

\footnotetext{
${ }^{9}$ Outras informações sobre o papel do grupo gestor podem ser acessadas em: Bona, Hanisch e Marques (2011).

${ }^{10}$ Descrição detalhada da metodologia pode ser acessada em HANISCH Et Al (2014a/B).
} 
Ocorreu no período de 2011 a 2014, com avaliação contínua da produção de pasto por dois anos, características do solo no início e final do experimento e caracterização do estrato arbóreo e do nível de sombreamento ao longo do ano.

O segundo experimento (Desempenho da grama Axonopus catharinensis (missioneiragigante) em áreas de caíva com predominância de araucária e com uso de pó de basalto) foi implantado em uma propriedade rural em Canoinhas e conduzido de 2013 a 2015. Contou com parceria da Embrapa Florestas e da Universidade Federal do Paraná (UFPR).

\section{RESULTADOS E DISCUSSÃO}

\section{CONHECER PARA MELHORAR: A CARACTERIZAÇÃO DAS CAÍVAS}

Apesar da expressiva representatividade das caívas na região, pouco se sabia sobre as mesmas até 2007, nem mesmo sobre sua caracterização ambiental. Através do levantamento florístico realizado em cinco áreas de caíva em 2008 e 2009, foi confirmado seu papel para a conservação de espécies arbóreas nativas, mesmo com a presença de animais há longo tempo. As espécies florestais de maior valor de importância foram araucária, erva-mate, imbuia, pimenteira e guamirim, típicas de FOM. A densidade de indivíduos arbóreos com diâmetro à altura do peito acima de $5 \mathrm{~cm}$ foi variável, mas bastante alta, sendo, em cada uma das cinco áreas, de 978, 833, 529, 459 e 217 indivíduos/ha (HANISCH et al., 2010). Esses resultados aproximam-se de valores encontrados para áreas de florestas em outros estudos semelhantes em áreas de FOM (VIBRANS et al., 2013).

A pastagem naturalizada das caívas é formada predominantemente por espécies pertencentes aos gêneros Paspalum e Axonopus (Poaceae) e Desmodium (Fabaceae), além de espécies não forrageiras. Há um grande campo de trabalho na identificação das espécies forrageiras que compõem as pastagens naturalizadas das áreas de caíva.

Através dos levantamentos iniciais foi determinado que o sombreamento do estrato herbáceo nas caívas é muito variável, seja em função da época do ano e do horário do dia, podendo ser radicalmente diferente entre pequenas distâncias da mesma área. Não raro são encontrados valores de $100 \%$ de sombreamento na maior parte do dia, dentro das áreas de caíva, o que inviabiliza a melhoria das pastagens em função da ausência de radiação fotossinteticamente ativa para as plantas.

Os resultados das análises de solo indicaram que os solos naturais das caívas são extremamente ácidos, sendo encontrados com frequência solos com $\mathrm{pH}$ entre 4 e 4,5. Apresentam também, baixa saturação de bases e de teores de fósforo. No entanto, destaca-se nos solos das caívas o alto teor de matéria orgânica do solo (acima de 4\%) e de potássio.

Apesar de essas características serem dependentes do material de origem, elas tendem a se acentuar pelo uso intensivo e sem a devida reposição de nutrientes. Nas caívas com manejo tradicional a única forma de reposição de nutrientes no solo tem se dado ao longo de dezenas de anos, através dos excrementos dos animais e da decomposição da vegetação. 


\section{A CONSTRUÇÃO DA PROPOSTA TECNOLÓGICA: AS CAÍVAS COMO SISTEMAS SILVIPASTORIS}

A produção animal a pasto exige do produtor rural um manejo adequado da pastagem, de forma a ofertar uma alta quantidade de massa foliar aos animais, com um nível adequado de qualidade da mesma. Em áreas de caíva, atenção redobrada deve ser dada a essa questão, uma vez que a maioria das espécies de pastagens adaptadas a essas áreas, devido às condições de stress presentes (sombra, baixa fertilidade), tendem a formar estruturas reprodutivas mais rapidamente, perdendo qualidade.

O uso do piqueteamento de pastagens é utilizado para que os animais só consumam o pasto quando as plantas atingirem uma altura pré-determinada e que deve ser a que lhe confere maior quantidade de folhas associada à alta qualidade da forragem. Uma vez rebaixado o pasto, os animais deixam o piquete e retornam somente quando o mesmo voltar à altura pré-determinada. Ou seja, os animais permanecem poucas horas em cada piquete (no máximo 24 horas) e retornam após períodos variáveis. Em caívas, esse manejo tem uma importância adicional, uma vez que pode contribuir para a regeneração natural das espécies nativas da floresta.

Outra estratégia importante no manejo do ambiente pastoril se dá através do uso de adubações, para que a pastagem atinja a altura desejada em um determinado espaço de tempo conhecido. Nas áreas de caíva, em função das características químicas do solo e da impossibilidade de revolver o solo devido à presença das árvores e o excesso de raízes, foi proposto o método de adubação em cobertura. Esse método consiste em aplicar doses muito menores que a recomendação (em torno de $1 / 4$ a $1 / 5$ da dose recomendada) diretamente sobre a pastagem naturalizada, sem incorporação mecânica da adubação ao solo.

Além do não revolvimento do solo por meio de aração ou subsolagem para não prejudicar as raízes arbóreas, houve também consenso entre as instituições envolvidas, em se utilizar apenas insumos agroecológicos, que apresentam solubilidade menor. No entanto, ainda havia a necessidade de testar o efeito de diferentes fontes de insumos orgânicos.

Como terceira estratégia de melhoramento das pastagens nativas em caívas, foi inserida a questão da sobressemeadura com pastagens anuais de inverno, iniciando-se o trabalho com azevém, ervilhaca e trevo-branco (este último nas áreas que já haviam recebido adubação há mais tempo).

Dessa forma, a proposta tecnológica de melhoria de caívas passou a ser definida como "Caívas melhoradas" cujo conjunto de técnicas envolve piqueteamento, adubação com diferentes fontes orgânicas e sobressemeadura de pastagens de inverno. Os resultados dos experimentos da fase 1 (2007-2008) e da fase 2 (2008-2009) estão apresentados nas Figuras 3 e 4. Como não houve diferença entre os diferentes insumos utilizados, estão sendo apresentas as médias dos tratamentos com adubação para cada período. 
Figura 3 - Produção de pasto no período primavera/verão 2007/2008 em caívas piqueteadas, sobressemeadas, com adubação (caíva melhorada) e sem adubação (caíva tradicional)

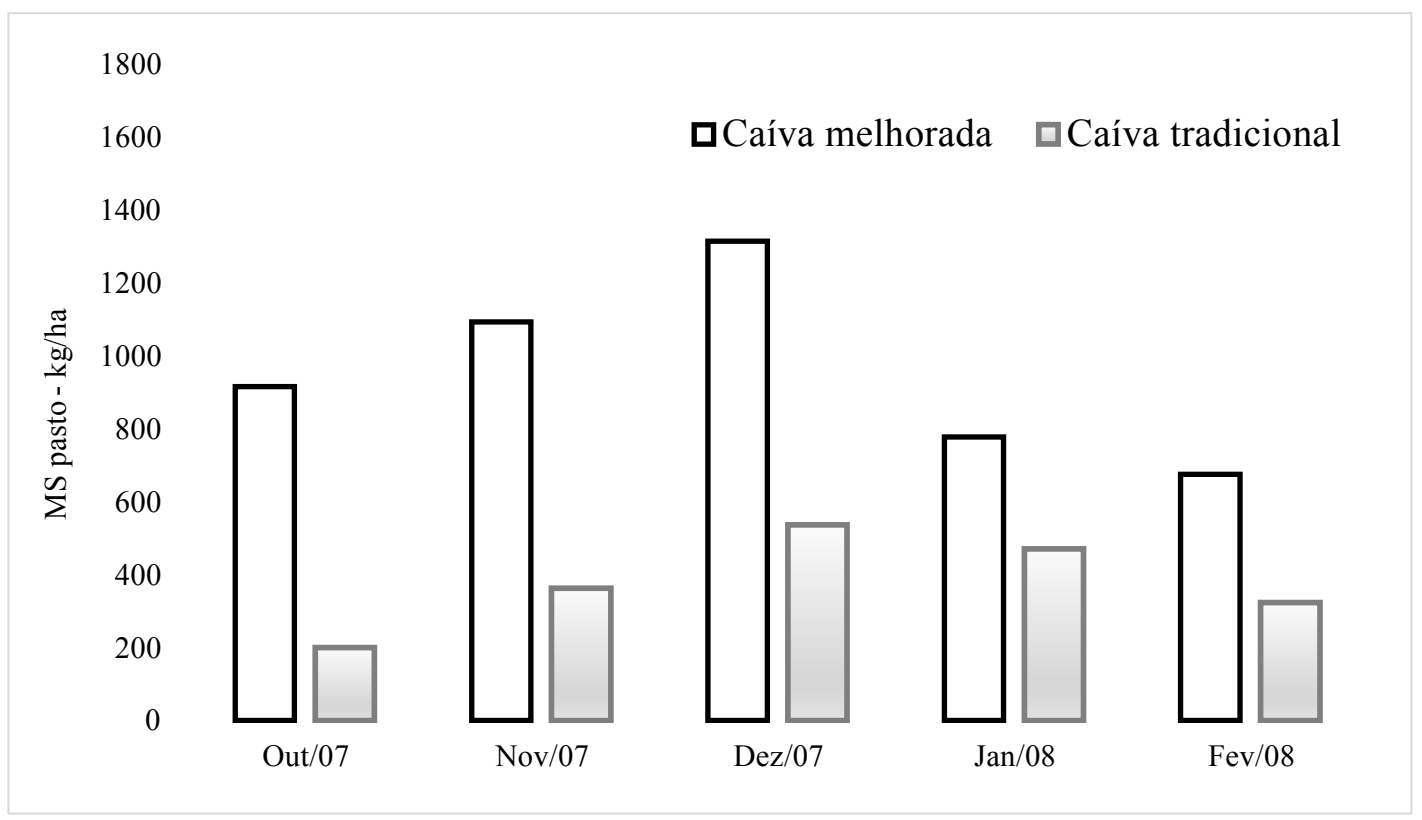

Fonte: Dados da Pesquisa (2016)

Figura 4 - Produção de pasto no período primavera/verão 2008/2009 em caívas piqueteadas, sobressemeadas, com adubação (caíva melhorada) e sem adubação (caíva tradicional)

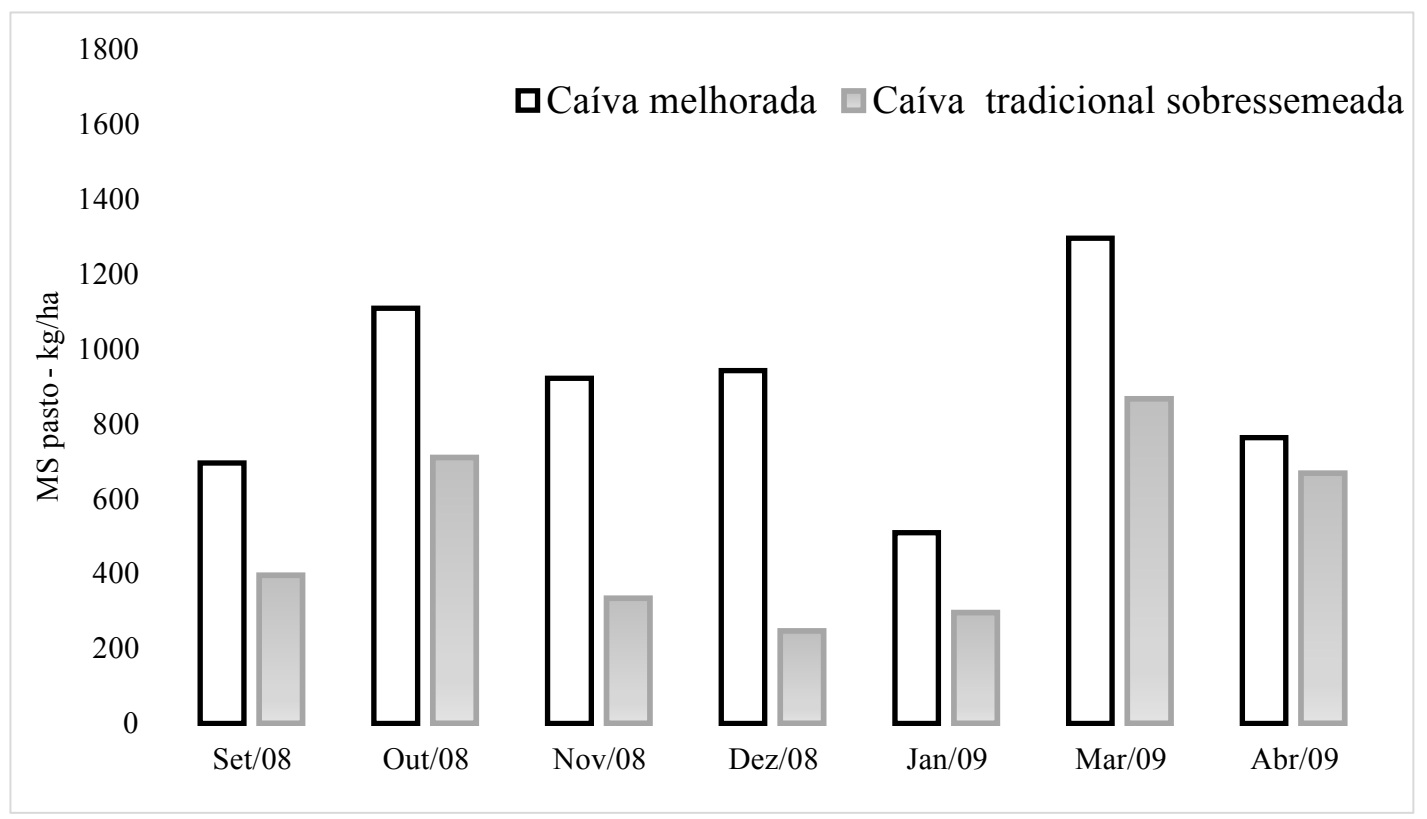

Fonte: Dados da Pesquisa (2016)

Os resultados indicaram que, independentemente da fonte utilizada, há resposta da pastagem à adubação, com aumento de mais de $100 \%$ da produção de forragem. A sobressemeadura é uma prática eficaz, pois permite a utilização das caívas durante os meses 
de inverno e primavera, período em que naturalmente não há produção de forragem, uma vez que as pastagens naturalizadas são predominantemente espécies estivais.

A produção total de pasto foi de 2.400 e $5.000 \mathrm{~kg} /$ ha de MS, respectivamente, para caíva tradicional (sem adubação) e caívas adubadas, independentemente da fonte. A caíva melhorada apresentou resultados próximos aos observados em campo nativo a pleno sol, com uso de esterco líquido de suíno (SCHEFFER-BASSO; SCHERER; ELLWANGER, 2008) o que permite inferir a validade do uso de insumos agroecológicos aplicados em cobertura para aumento na produção de pastagens nativas em áreas de caíva.

Embora um aumento de produção fosse esperado, o fato de não haver diferenças entre os insumos - embora apresentassem composições bastante diferentes - indica a complexidade do ambiente de caíva e a necessidade de aprofundamento das pesquisas.

Nos três tratamentos com adubação, ao final de cada experimento, as análises de solo revelaram aumento nos teores dos nutrientes, independentemente da fonte, comprovando que a aplicação dos mesmos possibilita melhoria das características químicas do solo, o que se reflete na produção de biomassa da pastagem.

Um efeito que inicialmente não era esperado, em função da aplicação de doses baixas dos insumos agroecológicos, era resposta nas árvores. No entanto, visualmente foi possível verificar que as árvores de erva-mate presentes nas áreas experimentais passaram a apresentar aspecto mais produtivo, com mais folhas verdes, menos galhos secos e maior vigor aparente. Esse resultado adicional levou os trabalhos para a fase seguinte: a melhoria das caívas em áreas com predominância de erva-mate.

\section{O SOMBREAMENTO NAS CAÍVAS E O PLANEJAMENTO DAS ÁREAS A SEREM MELHORADAS}

As pastagens das áreas de caíva são naturalmente submetidas a diferentes níveis de sombreamento, que podem variar de $20 \%$ a $100 \%$. Na primeira e segunda fase das pesquisas em áreas de caíva, foram utilizadas áreas em que o sombreamento máximo foi de $60 \%$, com média na primavera de $40 \%$ de sombra. Isso significa que, em algum momento do dia, as plantas recebiam luz, em quantidade e qualidade variáveis.

Na terceira fase foi selecionada uma área com predominância de erva-mate. O objetivo dessa fase experimental foi verificar se com o aumento do sombreamento provocado pelo crescimento da erva-mate até a época da colheita, haveria condições para a prática do melhoramento da pastagem nas caívas. Dessa forma, foi implantado um experimento em área com sombreamento médio de $80 \%$ na primavera. A interferência na disponibilidade de luz às plantas refletiu diretamente na produtividade da pastagem (Figura 5 e Figura 6). 
Figura 5 - Produção de pasto no período inverno/primavera 2010 em área de caíva com alta densidade de ervamate, com adubação (caíva melhorada) e sem adubação (caíva tradicional)

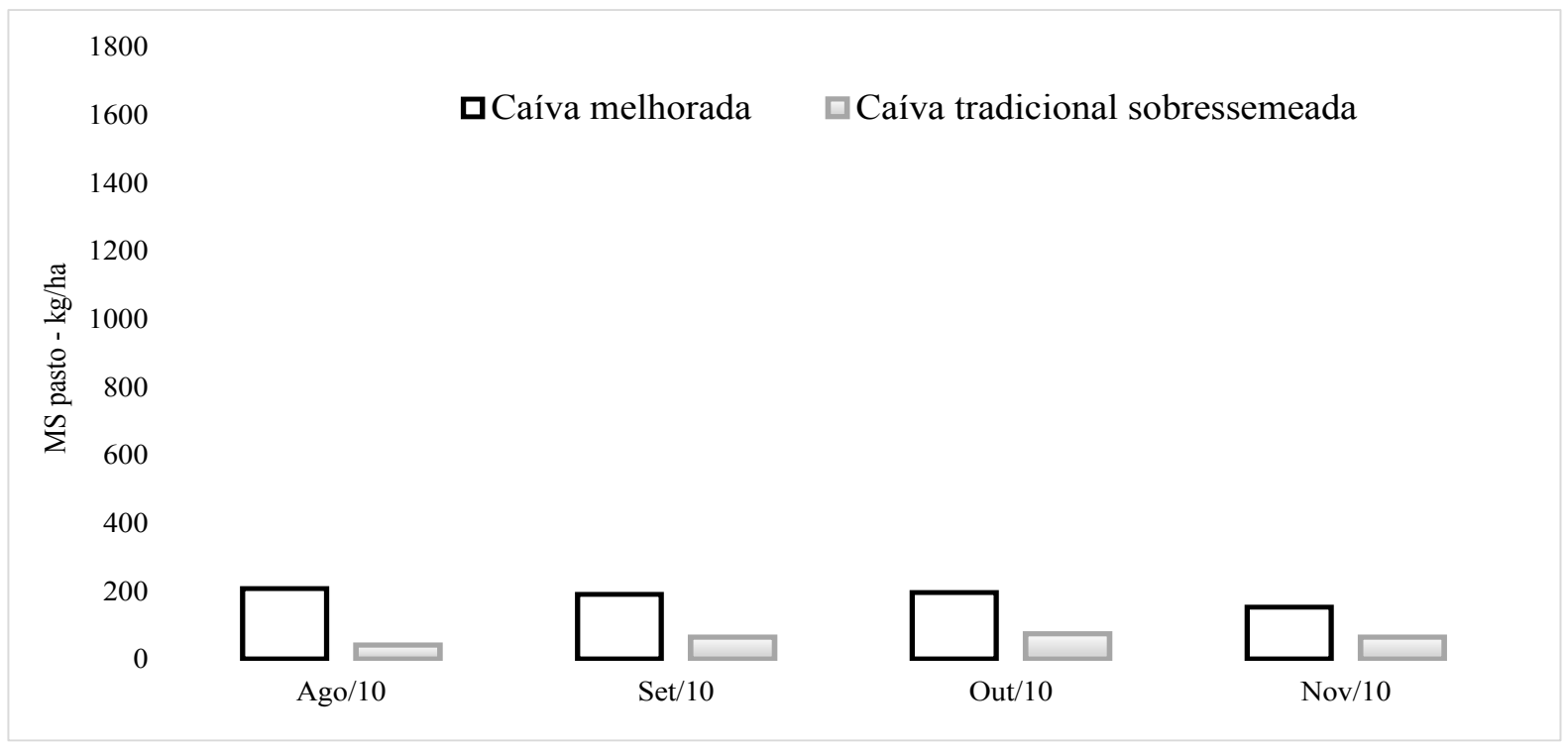

Fonte: Dados da Pesquisa (2016)

Figura 6 - Produção de pasto em área de caíva com alta densidade de erva-mate, com adubação (caíva melhorada) e sem adubação (caíva tradicional)

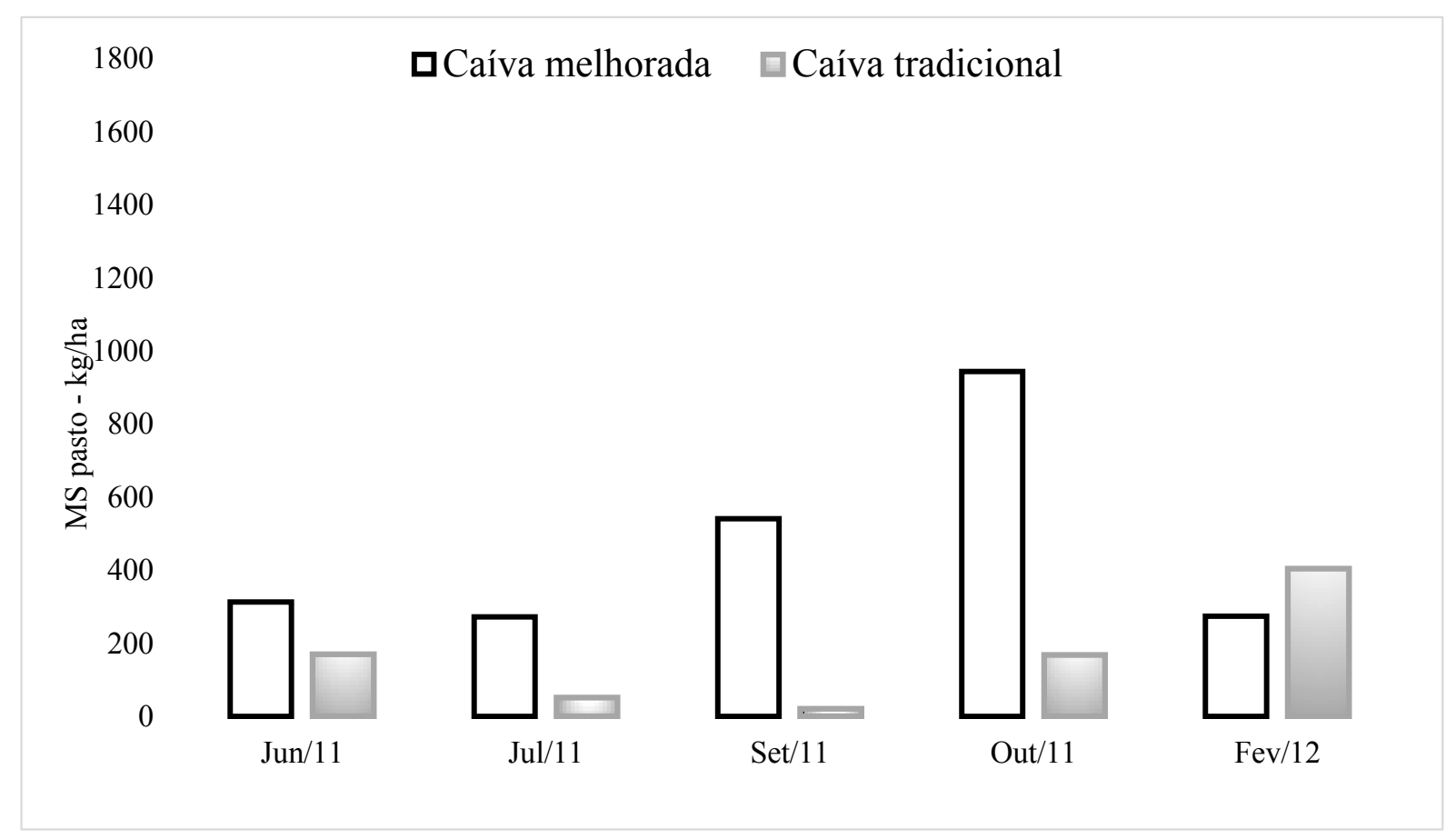

Fonte: Dados da Pesquisa (2016)

A média de radiação fotossinteticamente ativa foi de 105,4 e $665 \mathrm{mmol} / \mathrm{m}^{2} / \mathrm{s}$ respectivamente nas áreas sombreadas e não sombreadas, dentro da área experimental (HANISCH et al., 2014). Ou seja, as plantas forrageiras na sombra receberam seis vezes menos luz, em média, que as plantas que estavam nas áreas mais abertas e recebiam sol. Isso é

DRd - Desenvolvimento Regional em debate (ISSNe 2237-9029) 
semelhante ao que ocorre, por exemplo, dentro de áreas de reflorestamento adensado de pinus (SOARES; SARTOR; ADAMI, 2009). Como consequência, a produção da massa seca do pasto de inverno foi, em média, de $800 \mathrm{~kg} / \mathrm{ha}$ durante todo o período de crescimento. Esse valor corresponde a produção de pastagem em áreas de sistema silvipastoril onde a densidade de árvores é muito alta (OTTO; MOTTA; REISSMANN, 2009) e é considerado muito baixo, sendo quase três vezes inferior ao obtido nos experimentos anteriores em caívas com sombreamento moderado (Figura 3 e 4 ).

Até mesmo a produção da pastagem naturalizada no verão (Figura 6, corte fev/12) foi $50 \%$ inferior que nas demais caívas com menor sombreamento, tanto na caíva adubada (melhorada) quanto na tradicional, indicando que o sombreamento é o fator mais importante a ser considerado no momento da definição de quais áreas de caíva podem ser melhoradas.

\section{A PESQUISA PARTICIPATIVA NO PROCESSO DE MELHORIA DA PRODUÇÃO ANIMAL EM CAÍVAS}

O processo tecnológico de melhoria da produção animal em caívas comprovou ser efetivo no aumento da produção de forragem nestas áreas, desde que sejam adotadas três estratégias simultaneamente: piqueteamento, sobressemeadura com forrageiras de inverno e adubação com insumos agroecológicos em cobertura (Figura 7).

Figura 7 - Produção total de pasto em caíva tradicional e caíva melhorada com diferentes densidades de sombra, em diferentes anos

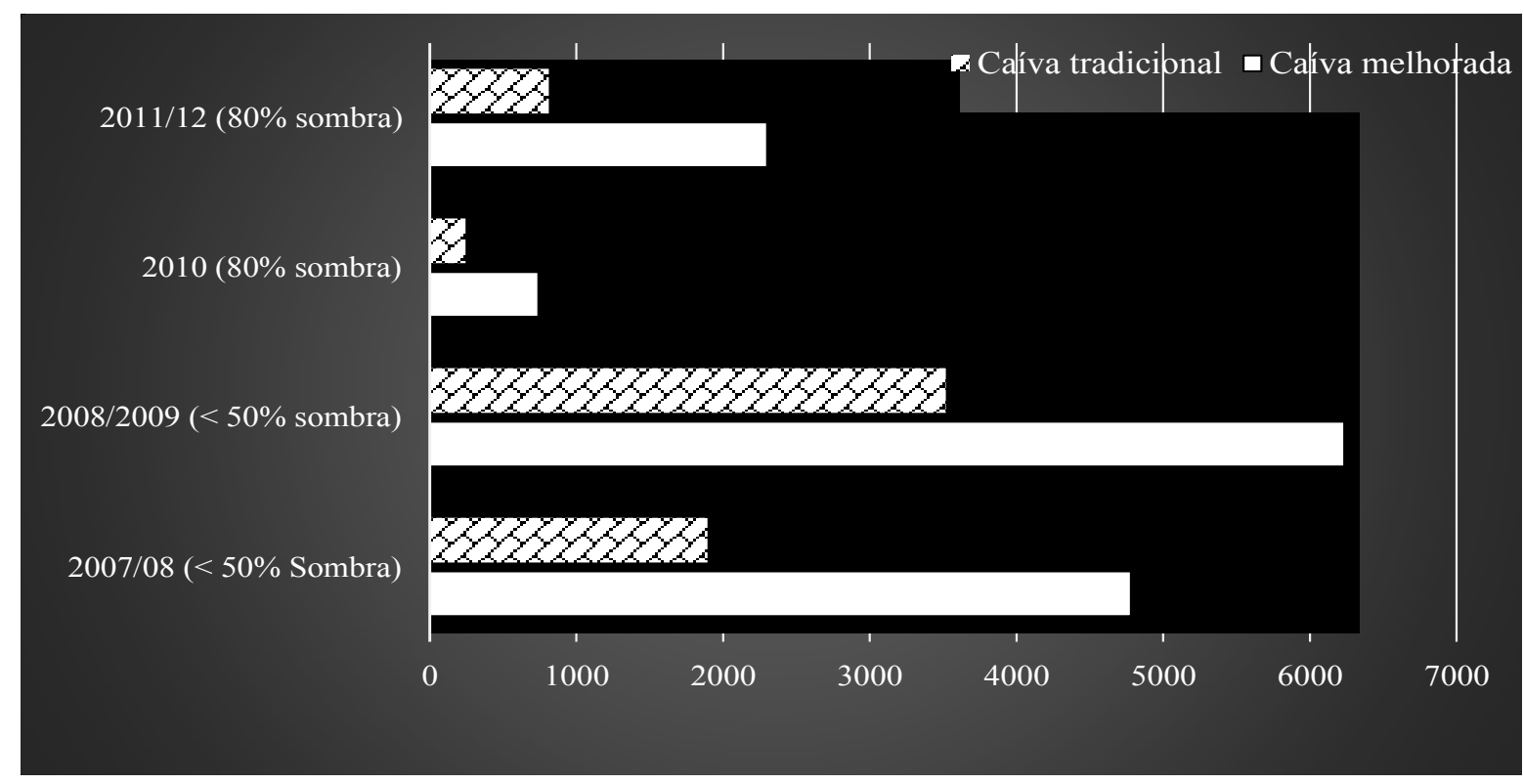

Fonte: Dados da Pesquisa (2016)

O piqueteamento isoladamente permite o aumento da pastagem, mas exige períodos de descanso muito prolongados, o que na prática inviabiliza seu uso. A sobressemeadura de inverno sem a prática da adubação também é inviável, uma vez que a produtividade obtida é baixa, não apresentando uma relação custo/benefício positiva em função dos custos das sementes. No entanto, o uso integrado das três estratégias permite dobrar a produção de pasto, 
sem aparentemente interferir de forma negativa no estrato arbóreo, promovendo melhoria visual da erva-mate e redução do consumo de folhas de árvores e quebra de galhos, uma vez que os animais tem pastagem disponível em maior quantidade e qualidade e permanecem por períodos muito curtos em cada piquete.

No entanto, o parâmetro fundamental, sem dúvida, para a tomada de decisão sobre qual área de caíva deve ser melhorada, é o nível de sombreamento, sendo que áreas com alta densidade de árvores e sombreamentos acima de 50\% não devem ser utilizadas com esse fim.

O resultado do Diagnóstico Rápido Participativo realizado com o Grupo Gestor das Caívas ao final da segunda fase da pesquisa confirmou a validade dos resultados obtidos nos experimentos. Isso porque as famílias visualizavam os resultados diretamente na produção animal (leite), confirmando ou não a efetividade e aplicabilidade dos resultados.

Quadro 1 - Resultado do Diagnóstico Rápido Participativo realizado com o Grupo Gestor das Caívas, após dois anos de trabalho conjunto

\begin{tabular}{|c|c|}
\hline PONTOS POSITIVOS & PONTOS NEGATIVOS \\
\hline $\begin{array}{l}\text { Aumento do pasto de inverno; } \\
\text { Aproveitamento de uma área que ficava sem renda } \\
\text { no inverno; } \\
\text { Área que no inverno passou a ter valor sem destruir } \\
\text { a natureza; } \\
\text { Produção de pastagem sem precisar mexer a terra; } \\
\text { Uso do piqueteamento das pastagens; } \\
\text { Geração de renda sem prejudicar o meio ambiente; } \\
\text { A introdução da pastagem perene de missioneira- } \\
\text { gigante nas caívas apresentou bom } \\
\text { desenvolvimento; } \\
\text { Melhoramento das pastagens nativas; } \\
\text { Amizades conquistadas; } \\
\text { Aprender pela troca de experiências entre as } \\
\text { famílias }\end{array}$ & $\begin{array}{l}\text { O pasto de verão foi ruim, não respondeu à } \\
\text { adubação; } \\
\text { A introdução da pastagem perene de hemarthria } \\
\text { Flórida não deu certo; } \\
\text { Muitas invasoras quando se mexe com o solo; } \\
\text { A grama nativa volta muito rápido quando se } \\
\text { mexe com o solo. }\end{array}$ \\
\hline
\end{tabular}

\section{Como vê o FUTURO DAS CAÍVAS}

- Como uma área conservada, tendo renda com bom pasto, sem precisar se tornar lavoura.

- Ampliar áreas de caíva com mais missioneira-gigante, a partir dos conhecimentos adquiridos com a pesquisa;

- Pensar em fazer consórcio com outras espécies nativas, animais, florestas e frutas;

- Incluir caíva como reserva legal para poder trabalhar sem se preocupar;

- Continuar usando a caíva como aprendeu na pesquisa

Fonte: Dados da Pesquisa (2016)

A realização dos experimentos em áreas de caívas típicas da região, através do processo de pesquisa participativa, permitiu aos pesquisadores e técnicos o suporte do conhecimento tradicional das famílias envolvidas, o que muitas vezes foi fundamental no processo de avaliação dos resultados. Além disso, por ser uma área nova do conhecimento, envolvendo diversos aspectos ecológicos e de interação entre sistemas, a integração de 
diferentes profissionais na equipe contribuiu para a condução dos experimentos e para uma análise mais aprofundada dos resultados obtidos.

Outra vantagem da pesquisa participativa é a contínua geração de demandas. Neste caso, com o sucesso do processo da "caíva melhorada" no período da primavera, percebeu-se que a pastagem naturalizada não respondeu na mesma expectativa ao manejo adotado, o que foi essencial para a continuação dos trabalhos e a busca da melhoria da produção animal no período de verão.

\section{A MISSIONEIRA-GIGANTE E A SUSTENTABILIDADE DAS CAÍVAS}

Os resultados dos dois experimentos com missioneira-gigante em áreas de caíva estão em análise. No entanto, já é possível confirmar a adaptação dessa espécie para as áreas com sombreamento moderado, sendo obtidos resultados de produção acima de 8 t/ha de massa seca por ano. A forma de implantação que permite seu estabelecimento sem a concorrência de invasoras tem sido o uso de herbicida dessecante sobre a pastagem naturalizada, com posterior plantio em covas das mudas da pastagem de missioneira-gigante.

Os impactos dessa tecnologia sobre a regeneração natural da floresta estão sendo avaliados desde 2014. Até o momento os resultados indicam que com o manejo de piqueteamento e adubação é possível reestabelecer a regeneração nas caívas após a introdução da nova pastagem. No entanto, como nova tecnologia, demanda que sejam seguidos todos os critérios técnicos, em especial em relação ao período e forma de aplicação do herbicida, bem como a forma de implantação da pastagem.

\section{A MELHORIA DA PRODUÇÃO ANIMAL E A VIABILIZAÇÃO DOS CORREDORES ECOLÓGICOS NO PLANALTO NORTE CATARINENSE}

Os resultados obtidos com o processo de melhoria da produção animal nas áreas de caíva criados pela Epagri/EECan com apoio de diversas entidades é um instrumento importante para a efetivação dos Corredores Ecológicos na região, por três aspectos:

1) É uma tecnologia de baixo impacto ambiental e adequada resposta produtiva, o que concilia a conservação das caívas ao aumento da geração de renda nestas áreas;

2) Com a melhoria das áreas de caíva menos sombreadas, ocorre aumento da produção animal, com redução da área anteriormente ocupada pelos animais, e consequentemente redução do trabalho humano na propriedade. Dessa forma, áreas significativas de caíva (mais fechadas) permanecem na propriedade com o viés apenas de conservação e uso florestal;

3) Um aspecto relevante observado nas propriedades que adotam a melhoria da produção animal em caívas é a melhoria do sistema produtivo como um todo, ou seja, aumenta-se o uso de pastagens perenes também nas áreas a pleno sol, com adoção de piquetes, uso correto do solo e da água, e uso de adubação. Dessa forma, criam-se espaços mais sustentáveis entre os corredores/caívas, com uso de 
tecnologias de menor impacto e maior conservação ambiental, refletindo na sustentabilidade e conservação da paisagem como um todo.

\section{CONSIDERAÇÕES FINAIS}

Com o desenvolvimento dos estudos nas caívas ao longo de quase uma década fica evidente a oportunidade de avanço científico e tecnológico em um sistema tradicional de manejo e uso da floresta.

A conservação das caívas tem sido buscada a partir de práticas de manejo da pastagem, aumento da diversidade de espécies e melhoria da qualidade do solo. As consequências diretas são um maior volume de forragem disponível aos animais e com melhor qualidade, resultando por sua vez em aumento da produção e da renda.

Com essa estratégia associada ao programa de Corredores Ecológicos será possível estimular um redesenho ambiental, criando pequenos mosaicos dentro e entre as propriedades rurais, preservando nascentes e outros mananciais. Qualidade ambiental associada a maiores rendimentos econômicos são benefícios que certamente contribuirão tanto para a melhoria do bem-estar das famílias agricultoras quanto para o desenvolvimento regional.

\section{REFERÊNCIAS}

BONA, L. C.; HANISCH, A. L.; MARQUES, A. C. Melhoramento de caívas no Planalto Norte de Santa Catarina. Revista Agriculturas, v. 8, p. 6-11, 2011.

FERREIRA, E. R. N. C.; ALMEIDA, J. A.; MAFRA, A. L. Pó de basalto, desenvolvimento e nutrição do feijão comum (Phaseolus vulgaris) e propriedades químicas de um Cambissolo Húmico. Revista de Ciências Agroveterinárias. v. 8, n. 2, p. 111-121, 2009.

FUNDAÇÃO DO MEIO AMBIENTE (FATMA). Corredores Ecológicos. Disponível em $<$ http://www.fatma.sc.gov.br/conteudo/apresentacao>. Acesso em: 18 maio 2016.

HANISCH, A. L., BONA, L. C; MARQUES, A. C. Resposta de pastagens nativas à adubação com insumos agroecológicos em áreas de caíva no Planalto Norte Catarinense. Revista de Estudos do Vale do Iguaçu, v. 14, p. 123-138, 2009.

. et al. Produção de forragem em ecossistema associado 'caíva'em função da aplicação de cinza calcítica e fosfato natural no solo. Agropecuária Catarinense, v. 27, p. 63-67, 2014a.

et al. Atributos do solo afetados pela aplicação de cinza calcítica e fosfato natural em ecossistema associado caíva. Agropecuária Catarinense, v. 27, p. 70-75, 2014 b.

; MEISTER, L. A. Produção e qualidade da pastagem de Hemarthia altissima cv. Flórida em sistemas de produção de leite manejada com princípios agroecológicos. Revista Brasileira de Agroecologia, v. 4, p. 767-770, 2009. 
et al. Estrutura e composição florística de cinco áreas de caíva no planalto norte de

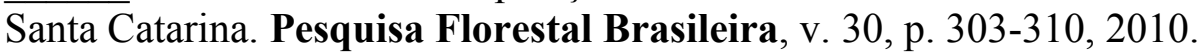

INSTITUTO BRASILEIRO DE GEOGRAFIA E ESTATÍSTICA - IBGE. Censo Agropecuário de 2006. Disponível em $<$ http://www.ibge.gov.br/home/ estatistica/economia/agropecuaria/censoagro/default.shtm $>$. Acesso em 02 de dezembro de 2013.

MARQUES, A.C. As paisagens do mate e a conservação socioambiental: um estudo junto aos agricultores familiares do Planalto Norte Catarinense. Curitiba, 2014. 434 p. Tese (Doutorado em Meio Ambiente e Desenvolvimento) UFPR.

MELLO, A. J. M.; PERONI, N. Cultural landscapes of the Araucaria Forests in the northern plateau of Santa Catarina, Brazil. Journal of Ethnobiology and Ethnomedicine, v. 11, p. 51, 2015.

OTTO, G. M; MOTTA, A. C. V; REISSMANN, C.B. Adubação nitrogenada em sistema silvipastotil álamo-pastagens de inverno. Revista Árvore, v. 33, n. 3, p. 433-441, 2009.

RIBASKI, J. et al. Sistemas silvipastoris: estratégias para o desenvolvimento rural sustentável para a metade Sul do Estado do Rio Grande do Sul. Colombo/PR: Embrapa Florestas, 2005. 8 p. (Embrapa Florestas. Comunicado Técnico, 150).

ROSOT, M. A. D. Manejo florestal de uso múltiplo: uma alternativa contra a extinção com Floresta com Araucária? Pesquisa Florestal Brasileira, n.55, p.75-85, 2007.

SCHEFFER-BASSO, S. M.; SCHERER, C. V., ELLWANGER, M. F. Resposta de pastagens perenes à adubação com chorume suíno: pastagem natural. Revista Brasileira de Zootecnia, v.37, n.2, p.221-227, 2008.

SOARES, A. B.; SARTOR, L. R.; ADAMI, P. F. et al. Influência da luminosidade no comportamento de onze espécies forrageiras perenes de verão. Revista Brasileira de Zootecnia, v.38, n.3, 'p.443-451, 2009.

VIBRANS, A.C. et al. Inventário Florístico Florestal de Santa Catarina. Floresta Ombrófila Mista. Blumenau: Edifurb, 2013, v. III.

Artigo recebido em: 10/06/2016

Artigo aprovado em: 11/07/2016 